\title{
Langerhans' cell histiocytosis with neurological injuries diagnosed from a single cutaneous lesion*
}

\author{
Andréa Bauer Bannach ${ }^{1}$ \\ Deusita Fernandes Gandia Soares ${ }^{1}$ \\ Tomás Zecchini Barrese ${ }^{4}$
}

\author{
Maria Teresa Fernandes Castilho Garcia ${ }^{2}$ \\ Antônio Luiz de Arruda Mattos ${ }^{3}$ \\ Marilda Aparecida Milanez Morgado de Abreu ${ }^{1}$
}

DOI: http:/ / dx.doi.org/10.1590/abd1806-4841.20174743

\begin{abstract}
Histiocytoses are rare diseases caused by the proliferation of histiocytes. The pathogenesis remains unknown and the highest incidence occurs in pediatric patients. The clinical presentations can be varied, in multiple organs and systems, and the skin lesions are not always present. Evolution is unpredictable and treatment depends on the extent and severity of the disease. It is described the case of a patient with various neurological symptoms, extensively investigated, who had its was diagnosed with histiocytosis from a single skin lesion. This report highlights the importance of Dermatology in assisting the investigation of difficult cases in medical practice.
\end{abstract}

Keywords: Eosinophilic granuloma; Histiocytosis; Histiocytosis, Langerhans-cell

\section{INTRODUCTION}

Histiocytosis are a group of rare heterogeneous diseases that have a common trait of the proliferation of histiocytes, which are reticuloendothelial system immune cells, derived from bone marrow and with phagocytic functions, which include macrophages and dendritic cells. ${ }^{1-3}$

The pathogenesis is unknown, but several theories have been developed, such as those suggesting its reactive or inflammatory nature and possible participation of genetic, viral, or immunologic factors. Familial cases have also been reported., ${ }^{1,4}$

Most cases take place during childhood (between one and two years of age), but disease onset may occur at any age. Its incidence is approximately five cases for each million children, which in adults reaches approximately two cases per million. The disease seems to be more frequent in men.
It is a broad clinical spectrum disorder that may affect several organs and systems and have an indolent or aggressive course. ${ }^{1}$

Histiocytosis are divided into three groups: (1) Langerhans cell histiocytosis (LCH), (2) non-Langerhans cell histiocytosis, and (3) malignant histiocytosis. The LCH group includes four sub-types: Hand-Schüller-Christian, Letterer-Siwe, Hashimoto-Pritzker, and eosinophilic granuloma (EG). ${ }^{2}$ Despite this classic division, some authors consider the four sub-types to be an evolutionary spectrum of the same disease, rather than different entities. ${ }^{1,4}$

This study describes a patient that exhibits multiple neurological symptoms, which have been extensively investigated, with an EG diagnosis based on a discrete skin lesion.

Received on 23.05.2015

Approved by the Advisory Board and accepted for publication on 11.10 .2015

* Work conducted at Hospital Regional de Presidente Prudente, Presidente Prudente, SP, Brazil.

Financial support: none.

Conflict of interest: none.

Dermatology Service, Hospital Regional de Presidente Prudente, Presidente Prudente, SP, Brazil.

Neurology Service, Hospital Regional de Presidente Prudente, Presidente Prudente, SP, Brazil.

Laboratory of Pathological Anatomy and Cytopathology, Hospital Regional de Presidente Prudente, Presidente Prudente, SP, Brazil.

Pathological Anatomy Service, Faculdade de Ciências Médicas da Santa Casa de São Paulo (FCMSCSP), São Paulo, SP, Brazil. 


\section{CASE REPORT}

A 45-year-old, white, male patient had exhibited, for the past two years, a partially ulcerated, circular, erythematous infiltrate plaque, measuring $2 \mathrm{~cm}$ in diameter, on the right scapular region (Figure 1).

For the past six years, he had been under neurological investigation for imbalance, diplopia, and slurred speech, and the case had evolved to an inability to walk, dysphagia, and dysarthria a short time before the last appointment. Nuclear magnetic resonance (NMR) imaging of the encephalon showed diffuse encephalic volumetric reduction and multiple hyperintense lesions in T2 and Flair, with no expansive nature, the majority of which impaired the cerebellar bridge and peduncles - findings considered to be unspecific. Muscular biopsy on the left biceps and biopsy of the cerebellar peduncle were inconclusive.

Histopathology of the skin lesion revealed the proliferation of histiocytic cells with increased volume and hyperchromatic nuclei, abundant cytoplasm and multinucleate areas exhibiting atypical mitosis figures, associated with eosinophils, attacking the entire reticular dermis (Figure 2).

The immunohistochemistry was positive for CD1A, protein S100 and langerin markers (Figure 3). Such results led to the LCH diagnosis, which explained the neurological condition.

The patient received pulse therapy with methylprednisolone, with was no response; later on, the patient developed diabetes insipidus.
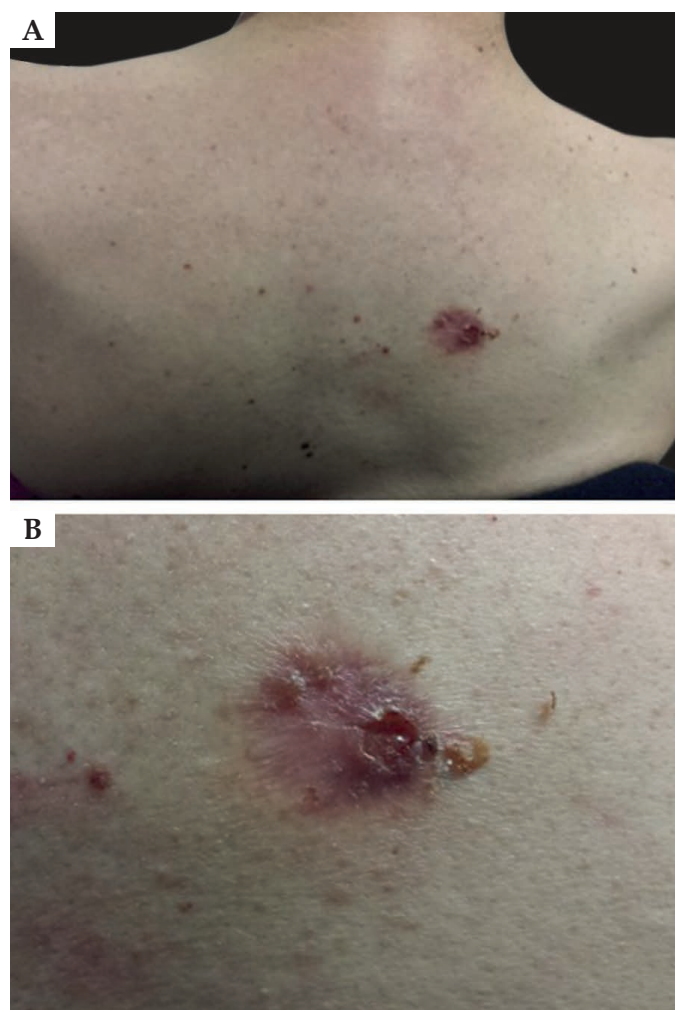

Figure 1: A - A partially ulcerated, circular, erythematous infiltrate plaque, measuring $2 \mathrm{~cm}$ in diameter, on the right scapular region; $\mathbf{B}$ - skin lesion detail
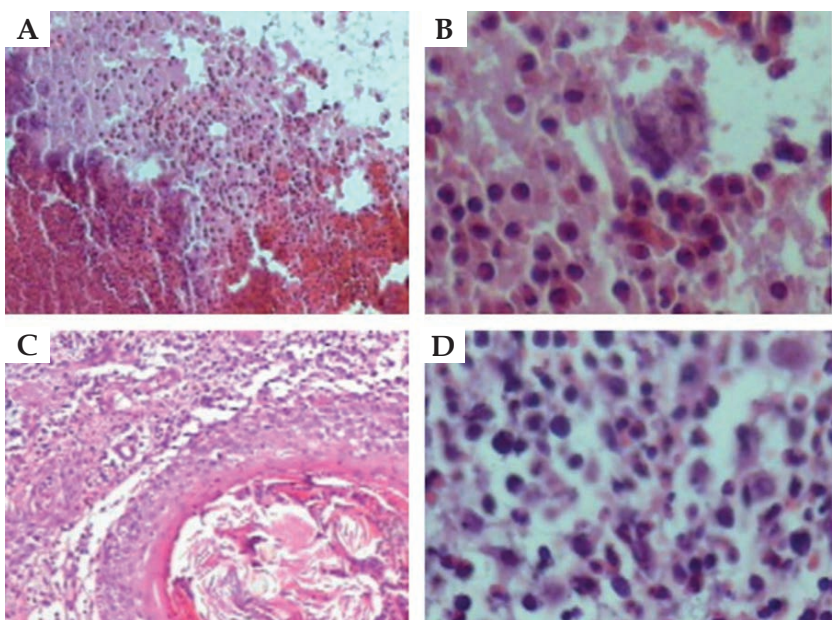

FiguRE 2: A - Fibrino-leukocytic scab permeable to numerous eosinophils (Hematoxylin \& eosin, x4); B - infiltrate with predominant eosinophils (Hematoxylin \& eosin, x10); C - lymphoplasma-eosinophil infiltrate around the pilous follicle (Hematoxylin \& eosin, $x 40$ ); D - infiltrate with numerous macrophages and eosinophils on the dermis (Hematoxylin \& eosin, $x 40$ )
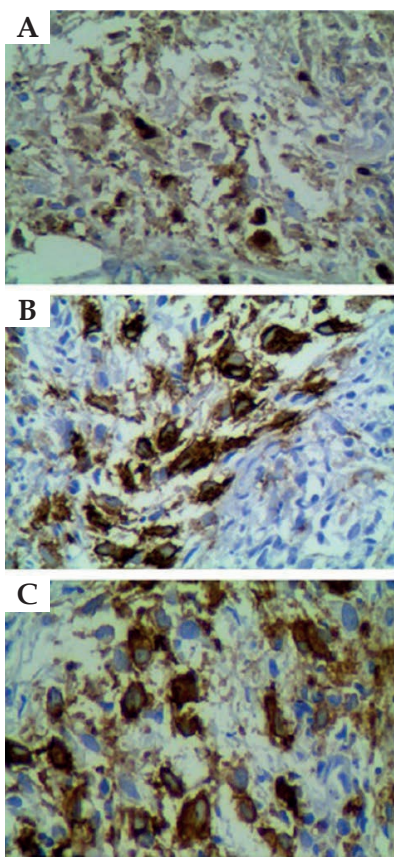

FIgURE 3: Positive immunohistochemical reaction following makers:

A - anti-protein $\mathrm{S} 100$

B - anti-langerin, and

C - anti-CD1A

$(\mathrm{a}, \mathrm{b}, \mathrm{c}$ : Immunohistochemical staining, X400)

Two months later, a new NMR of the encephalon revealed an expansive lesion with an extra-axial, right parietal calcification, involving the meninges and the internal bone plate, and compressing the encephalon, suggesting a bone lesion by histiocytosis (Figure 4). The patient was subjected to decompressive neurosurgery; chemotherapy was also indicated. However, the condition evolved with pneumonia, a worsened general medical condition, and death.

The histopathological examination of the calvarium and the dura mater (surgical piece) also revealed alterations that were compatible with $\mathrm{LCH}$, in addition to hemorrhage and necrosis areas, confirming they had been impaired by the disease. 


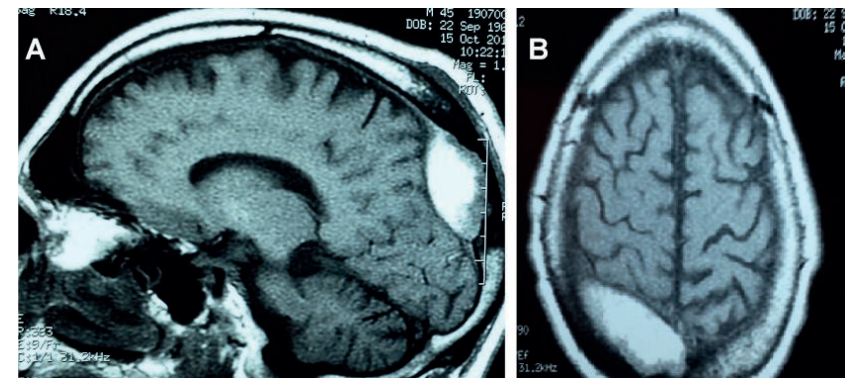

Figure 4: A) NMR of the encephalon in Flair sequence: sagittal section and B) axial section expansive lesion with calcic component is shown in the high parietal convexity on the right, extra-axial, involving the meninges and internal bone plate, with compressive effect on the encephalic parenchyma.

\section{DISCUSSION}

EG is the benign and localized form of $\mathrm{LCH}$, and is prevalent in children and young adults (five to thirty years of age). The most commonly affected areas are, sequentially, bones, skin, and lymph nodes. Skin lesions, if present, are in general erythematous-brownish papules, ulcerous-crusty plaques and lesions similar to those present in seborrheic dermatitis, located on the torso and scalp. When they regress, they leave hypochromia, atrophy, and alopecia. ${ }^{2,4}$ There may be lesions in the mucosa and ungual manifestations, all of which are unspecific.

Bones are the most common site for isolated occurrence ( $80 \%$ of the cases). Single, asymptomatic osteolytic lesions are predominant, preferably on the skull and on the ribs. Infiltration of retro-ocular bones causes exophthalmos, and maxillary lesions result in the appearance of floating teeth in simple X-rays. The disease may affect muscles, contiguous soft tissue, and, later, bone marrow, leading to pancytopenia. The occurrence of fever, arthralgia, weight

\section{REFERENCES}

1. Ferreira LM, Emerich PS, Diniz LM, Lage L, Redighieri I. Langerhans cell histiocytosis: Letterer-Siwe disease - the importance of dermatological diagnosis in two cases. An Bras Dermatol. 2009;84:405-9.

2. Quattrino AL, Silveira JCG, Diniz C, Briggs MC, Vilar E. Histiocitose de células de Langerhans: relato de caso e revisão da literatura. An Bras Dermatol. 2007;82:337-41

3. Campos MK, Viana MB, Oliveira BM, Ribeiro DD, Silva CMR. Histiocitose das células de Langerhans: experiência de 16 anos. J Pediatr (Rio J). 2007;83:79-86.

4. Garg A, Kumar P. Multisystem Langerhans cell histiocytosis in adult. Indian J Dermatol. 2012;57:58-60.

5. Wang X, Yang S, Tu P, Li R. A case of Langerhans cell histiocytosis in an adult with initial symptoms confined to the skin. Int J Dermatol. 2010;49:337-9.

6. Li Z, Yanqiu L, Yan W, Xiaoying Q, Hamze F, Siyuan C, et al. Two case report studies loss, and leukocytosis is also described. ${ }^{5,6}$

Alterations in the central nervous system are rare and are divided into three groups: (1) pituitary-hypothalamic system disorders (they are more common and determine diabetes insipidus), (2) mass effect symptoms (such as headache or convulsions), and (3) pontocerebellar symptoms (abnormal reflexes, ataxia, intellectual impairment, or dysarthria). ${ }^{7-9}$ In all of the groups, progression of neurological degeneration is variable. Delayed neuro-psychomotor development is common in children.

The diagnosis is based on clinical and histopathological aspects and is defined by immunoreactivity to CD1A, by the demonstration of Birbeck granules ("tennis-racket" shaped intracytoplasmic structures) under electronic microscopy or by positive langerin (CD207). 2,6,8

Treatment depends on the disease's extent and severity. ${ }^{1}$ For isolated skin lesion, nitrogen mustard or topical corticosteroids are used; systemic azathioprine, methotrexate and thalidomide or PUVA are also effective. For isolated bone lesions, curettage and radiotherapy are the treatment of choice. ${ }^{10}$ If systemic disease is present; corticosteroids, chemotherapy agents, interferon, and bone marrow transplant are options. Therapeutic failure after six weeks indicates a bad prognosis., ${ }^{2,3}$

Evolution is unpredictable, varying from spontaneous regression to rapid progression and death. The main factors for the worst prognosis are: early onset (in patients under two years of age), extensive disease, and organ failure. ${ }^{1,2}$ The most frequent causes of death are pulmonary and medullary disorder.

In the patient described in this study, skin and bone lesions were typical of EG. However, the exceptional neurological impairment was attributed to histiocytosis only after the skin lesion was been diagnosed, resulting in severe sequelae and death. The case reported reinforces the importance of dermatology in the investigation of difficult cases in medical practice. $\square$

of Langerhans cell histiocytosis with an analysis of 918 patients of Langerhans cell histiocytosis in literatures published in China. Int J Dermatol. 2010;49:1169-74.

7. Ng-Cheng-Hin B, O'Hanlon-Brown C, Alifrangis C, Waxman J. Langerhans cell histiocytosis: old disease new treatment. QJM. 2011;104:89-96.

8. Grana N. Langerhans cell histiocytosis. Cancer Control. 2014;21:328-34.

9. Proietto G, Amatetti M, Amerio P, Angelucci D, Feliciani C, Amerio P. Langerhans cell histiocytosis associated with diabetes insipidus: magnetic resonance imaging. Int J Dermatol. 1996;35:730-2.

10. Gabbay LB, Leite Cda C, Andriola RS, Pinho Pda C, Lucato LT. Histiocytosis: a review focusing on neuroimaging findings. Arq Neuropsiquiatr. 2014;72:548-58.

\author{
MAILING ADDRESS: \\ Marilda Aparecida Milanez Morgado de Abreu \\ RUA BRASIL, 1.599 \\ CENTRO \\ CEP 1790-000 DRACENA, SP \\ E-MAIL: marilda@morgadoeabreu.com.br
}

How to cite this article: Bannach AB, Garcia MTFC, Soares DFG, Mattos ALA, Barrese TZ, Morgado de Abreu MAM. Langerhans' cell histiocytosis with neurological injuries diagnosed from a single cutaneous lesion. An Bras Dermatol. 2017;92(4): 540-2. 